PONTIFÍCIA UNIVERSIDADE CATÓLICA DO RIO DE JANEIRO

Festivais de Música em Tempos de Pandemia Caso Festeja

Victória Gonçalves Marques da Costa

Trabalho de Conclusão de Curso

Centro de ciências socials - CCS

DePARTAMENTO de AdMINISTRAÇÃo

Graduação em Administração de Empresas 
Victória Gonçalves Marques da Costa

\section{Festivais de Música em Tempos de Pandemia Caso Festeja}

Trabalho de Conclusão de Curso

Trabalho de Conclusão de Curso, apresentado ao programa de graduação em Administração da PUC-Rio como requisito parcial para a obtenção do titulo de graduação em Administração.

Orientadora: Alessandra Baiocchi A. Corrêa

Rio de Janeiro

Junho de 2020. 
"Não é o mais forte que sobrevive, nem o mais inteligente, mas o que melhor se adapta às mudanças." (Charles Darwin) 


\section{Agradecimentos}

Eu poderia gastar as linhas desse espaço para relembrar e realçar todo meu esforço e dedicação com que levei o meu curso nos últimos anos. Conciliar a vida acadêmica com tudo que o mundo proporciona nos seus diversos âmbitos não é uma tarefa fácil. Mas a jornada deste curso passa pelo conceito mais básico de todos: administração. Administrar o tempo e a minha dedicação a cada solicitação vivida nos últimos tempos foi de longe uma tarefa difícil.

Trabalhar, estudar e viver, tudo isso ao mesmo tempo, não é fácil. Concluir este curso é a prova que consegui atravessar esse caminho. No entanto, reconheço que a minha vitória é fruto de esforços alheios dos meus metres, chefes, familiares e amigos. E aqui eu começo a agradecer ao meu pai, que em todo esse tempo jamais me deixou descansar, apresentando-me desafios, deixando-me distante do meu conforto e sempre me fazendo lembrar que sou absolutamente dona da minha própria Victória.

Agradeço à minha irmã Clarissa, pelo carinho, e cumplicidade sempre constante. Te amo, irmã. A todos os meus familiares pelo carinho e amor durante esses anos. Aos colegas e amigos da Som Livre, lugar que tem me dado a oportunidade de crescer e aprender. Obrigada. Aos meus professores da PUCRio, em especial a Alessandra Baiocchi, pelo tempo e suor dedicados.

Tudo isso é fruto de muita luta e felicidade. Obrigada. 


\section{Resumo}

Gonçalves Marques da Costa, Victória. Festivais de Música em tempos de pandemia: Caso Festeja. Rio de Janeiro, 2020. 33p. Trabalho de Conclusão de Curso - Departamento de Administração. Pontifícia Universidade Católica do Rio de Janeiro.

O presente estudo tem como objetivo investigar possibilidades para o mercado de eventos de música, diante dos desafios que enfrentou no momento de pandemia tendo como objeto de estudo o Festival Festeja. Para isso, foi realizada uma pesquisa exploratória, realizada em três estágios: No primeiro estágio foram consultados dados secundários que possibilitou um maior conhecimento do setor e seus atuais desafios além de embasar 0 desenvolvimento dos próximos passos da pesquisa. No segundo estágio, foi realizada uma entrevista com a equipe responsável pelo Festeja. No terceiro estágio foi realizada uma pesquisa com público de lives do setor. Dentre os principais achados podemos destacar uma mudança significativa no comportamento do consumidor, a constante necessidade de reinvenção do setor de música e a implementação de eventos híbridos.

Palavras- chave

Lives, Festival, Festeja, Pandemia. 


\section{Abstract}

Gonçalves Marques da Costa, Victória. Music Festivals in Times of Pandemic: Case Festeja. Rio de Janeiro, 2020. 33p. Course Completion Work - Administration Department. Pontifical Catholic University of Rio de Janeiro.

The present study aims to investigate possibilities for the music events market, given the challenges faced during the COVID-19 pandemic. Festeja Festival is the object os study. For this, an exploratory research was carried out, carried out in three stages: In the first stage, the study focused on secondary data to allow greater knowledge regarding the field and its current challenges. In the second stage, interviews were conducted with the team responsible for the festival. In the third stage, a survey was conducted with the public. The main results indicate a significant change in consumer behavior, the need for a constant reinvention of the music industry, implementation of hybrid events.

\section{Key-words}

Lives, Festival, Celebrate, Pandemic. 


\section{Sumário}

1 Introdução

2 Contexto e realidade investigada 2

2.1. Ambiente interno - Histórico e atualidade do Festival Festeja 2

2.2. Ambiente externo - Histórico e atualidades do setor 4

2.2.1. Mercado de festivais no Brasil 4

2.2.2. Momento atual: A pandemia do COVID-19 e suas consequências para os festivais de música no Brasil. $\quad 5$

3 Diagnóstico da situação-problema e oportunidades 9

3.1. Lives e YouTube 9

3.2. As maiores lives do YouTube são brasileiras 10

4 Passos metodológicos 14

4.1. Pesquisa com dados secundários 14

$\begin{array}{ll}\text { 4.2. Pesquisa com dados primários } & 14\end{array}$

5 Análise dos resultados $\quad 16$

5.1. Entrevista com a equipe do Festeja 16

5.1.1. Entrevista com Mariana 16

5.1.2. Entrevista com Rafael 17

5.2. Resultado da pesquisa com o público que assistiu lives de sertanejo

$\begin{array}{ll}\text { no último mês } & 18\end{array}$

6 Discussões e propostas $\quad 23$

6.1. A retomada do setor de música ao vivo 23

6.2. O futuro das lives 23

6.3. Alternativas para profissionais do mercado de eventos 24

6.4. Eventos híbridos 25 
7 Conclusão

Referências

Anexo 1

Anexo 2 
Índice de Figuras

Figura 1: Festival Festeja .................................................................. 2

Figura 2: Marília Mendonça no programa Festeja Brasil ................................. 3

Figura 3: Festeja Brasil - Brasília................................................................ 3

Figura 4: Comunicado do Lollapalooza .................................................... 6

Figura 5: Adiamento do Lollapalooza na mídia............................................... 6

Figura 6: Nota de adiamento do VillaMix ..................................................... 7

Figura 7: Nota de adiamento do Buteco ...................................................... 7

Figura 8: Live do Gusttavo Lima....................................................10 11

Figura 9: Resultado Jorge \& Mateus ................................................1112

Figura 10: Marília Mendonça ganha destaque no jornal "The New York Times" .$\underline{12} 13$

Figura 11: Live Marília Mendonça ............................................................ 13

\section{Índice de Tabelas}

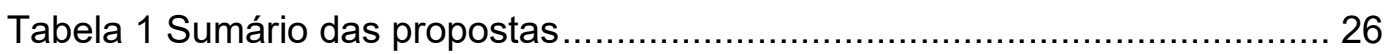




\section{Índice de Gráficos}

Gráfico 1: Média de festivais por região do Brasil......................................... 5

Gráfico 2: Faixa etária dos entrevistados ...........................................1819

Gráfico 3: Lives assistidas pela amostra .............................................1920

Gráfico 4: Lives que mais agradaram o público.......................................1920

Gráfico 5: Lives que menos agradaram o público....................................202 21

Gráfico 6: Continuar assistindo lives pós pandemia ..................................2021

Gráfico 7: Aceitar pagar por uma live ...............................................21z2

Gráfico 8: Voltar a frequentar eventos de imediato...................................21 22

Gráfico 9: Marcas que passaram a ser consumidas ...................................222 23 


\section{Introdução}

O Brasil é um país que recebe em média 1.928 festivais de música por ano (DATA SIM, 2019). O mercado de eventos de música é um dos mais importantes do entretenimento e em janeiro de 2020 foi projetado um crescimento da música ao vivo de $14 \%$, onde em 2023 as receitas de bilheteria excederiam a U\$25 bilhões no mundo (FACEBOOK, 2020; NIELSEN, 2019).

Em contrapartida, em dezembro de 2019 foi descoberto na China o COVID-19 (MINISTÉRIO DA SAÚDE, 2020). Um vírus altamente contagioso que em um curto período alcançou proporção internacional, forçando a população a mudar completamente as suas rotinas. $O$ setor viu suas atividades temporariamente suspensas e os funcionários precisaram encontrar novos meios de subsistir.

Este trabalho tem como objetivo investigar possibilidades futuras para o mercado de eventos de música diante dos desafios que enfrenta no momento. Todos os eventos que envolvem aglomeração foram temporariamente cancelados e a retomada do setor ainda está incerta. Diante deste cenário a pergunta de pesquisa deste projeto é: Quais são as possibilidades futuras para o mercado de eventos de música diante da crise que a pandemia do Covid-19 provocou no setor?

Para responder esta questão, o Festival Festeja será utilizado como objeto de estudo. O Festeja é um festival de música que reúne grandes artistas da música sertaneja e outros gêneros brasileiros. O evento criado pela gravadora Som Livre em 2012, atualmente possui setenta edições realizadas em cerca de trinta e cinco cidades e conta também com edições internacionais (FESTEJA, 2020).

Em 2020, todas as edições do festival foram canceladas e os organizadores passam a trabalhar com o retorno para 2021. O mesmo aconteceu para diversos outros festivais no Brasil e no mundo. Ademais, ainda há muita incerteza em relação às perspectivas do mercado no futuro. Diante deste contexto, este trabalho pretende apresentar propostas para o setor, auxiliando produtores, artistas, marcas patrocinadoras e demais atores envolvidos no setor de música ao vivo. 


\section{Contexto e realidade investigada}

\subsection{Ambiente interno - Histórico e atualidade do Festival Festeja}

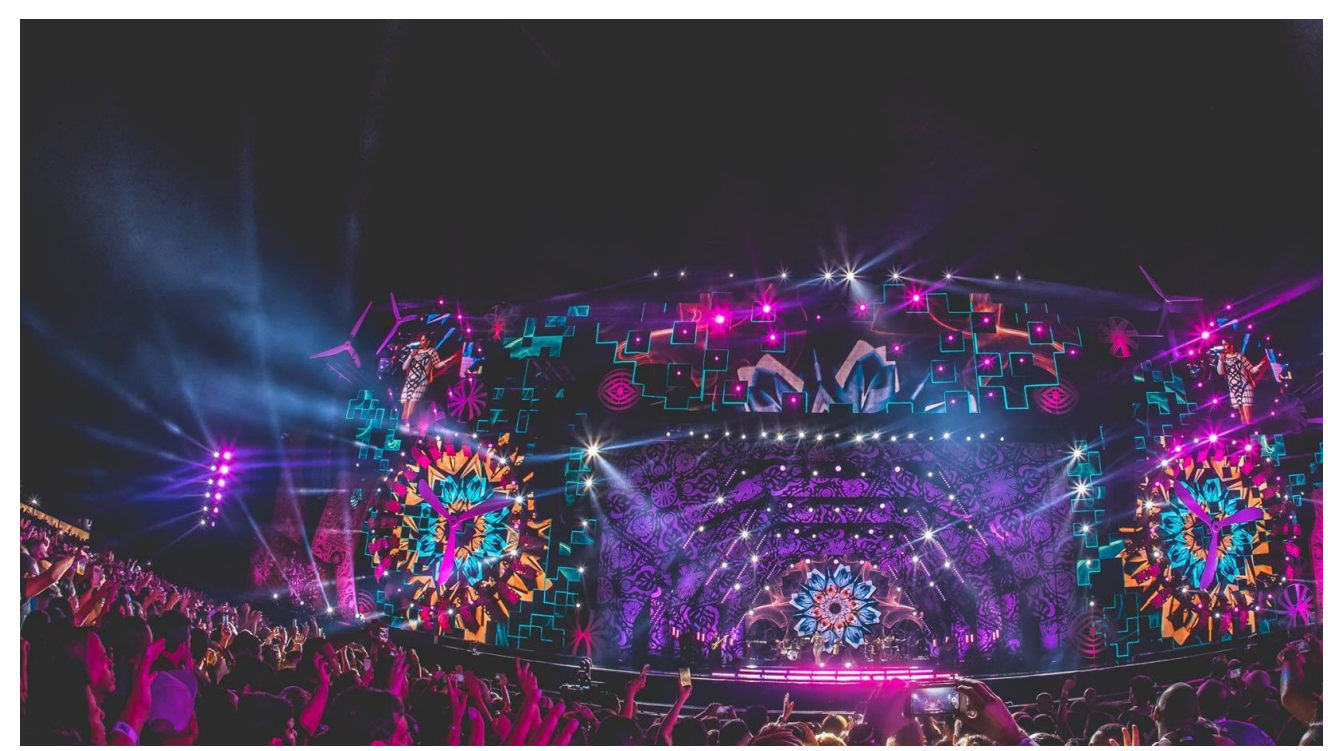

Figura 1: Festival Festeja

Fonte: Som Livre, 2020.

Um festival itinerante que celebra a música brasileira com todos os seus estilos. Esse é o Festeja, que desde sua estreia, em 2012, impactou mais de dois milhões de pessoas (Figura 1). O evento, criado pela Som Livre - Grupo Globo Comunicações S.A., já teve mais de setenta edições em cerca de trinta e cinco cidades, incluindo edições fora do Brasil, em países como Estados Unidos, Portugal, Bélgica e Inglaterra (FESTEJA,2020).

Originalmente criado para ser um festival sertanejo, o Festeja evoluiu junto com o crescimento do gênero no país. Hoje, o evento conta com um line-up ${ }^{1}$ variado, que inclui grandes nomes nacionais que representam toda a diversidade musical brasileira. Todas as edições contam com um headliner ${ }^{2}$ e com artistas regionais, respeitando e valorizando as preferências de cada cidade por onde

\footnotetext{
1 Line-up é a lista de artistas que tocam no festival.

2 Headliner é o artista principal de uma line-up.
} 
passa. Todos os anos, a maior edição do Festeja é gravada e exibida como especial de final de ano na programação da TV Globo, sob o nome de Festeja Brasil (FESTEJA, 2020) (Figura 2).

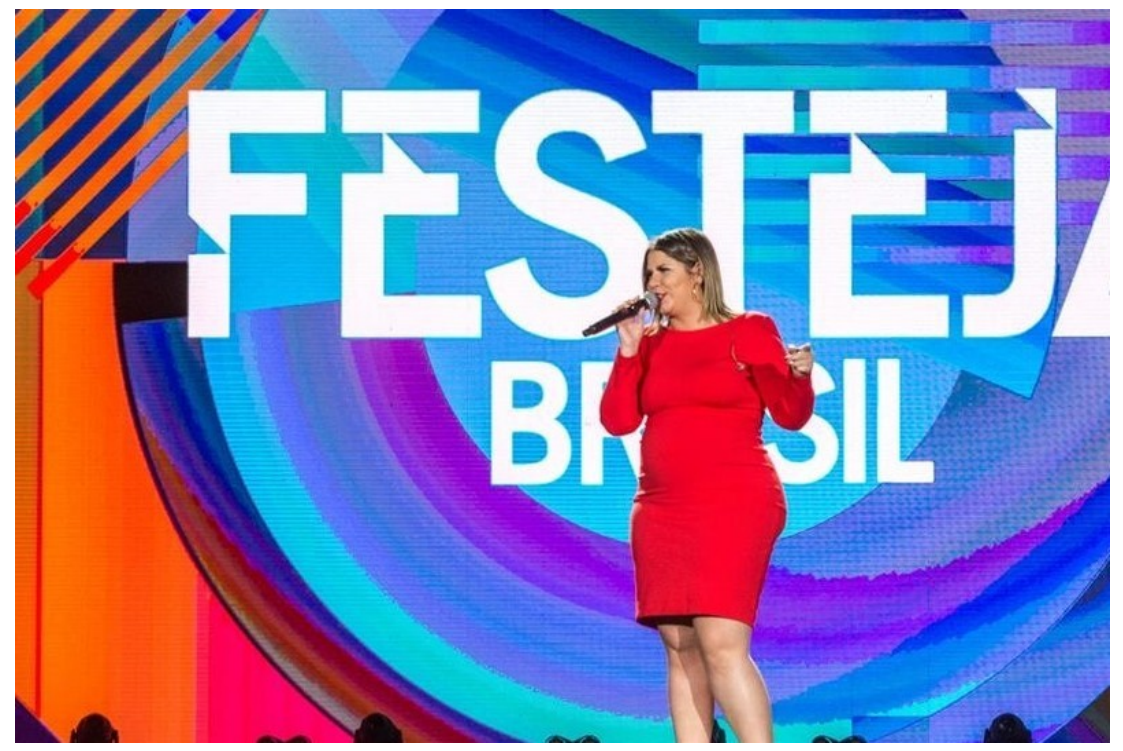

Figura 2: Marília Mendonça no programa Festeja Brasil

Fonte: TV Globo, 2020

Em 2019, foram realizadas oito edições: Juiz de Fora, Rio de Janeiro, Belo Horizonte, Recife, Fortaleza, Curitiba, São José do Rio Preto e Brasília (Figura 3). Marília Mendonça, Zé Neto \& Cristiano e Maiara \& Maraísa foram as atrações principais, revezando-se entre as cidades. Outros nomes que compuseram o line-up desse ano foram Ferrugem, Léo Santana, Dilsinho e Diego \& Victor Hugo (FESTEJA, 2020).

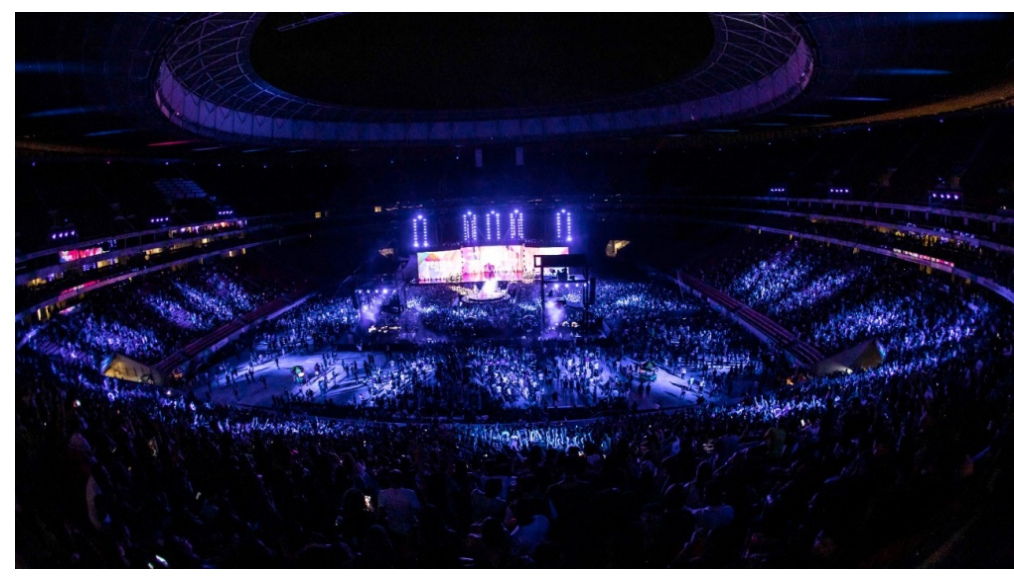

Figura 3: Festeja Brasil - Brasília

Fonte: Som Livre, 2020 
Para 2020, estavam previstas cinco edições do Festeja, em Fortaleza, Rio de Janeiro, São Paulo, Belo Horizonte e Brasília, e uma do Festeja Brasil, em Recife. A estimativa era receber, no total, 200 mil pessoas, mas devido à pandemia do COVID-19 todos os eventos de entretenimento foram suspensos por tempo indeterminado (informação verbal) ${ }^{3}$.

\subsection{Ambiente externo - Histórico e atualidades do setor}

\subsubsection{Mercado de festivais no Brasil}

O primeiro festival de música realizado no Brasil foi o Festival da Velha Guarda em 1954 na cidade de São Paulo. O festival teve uma excelente repercussão e abriu portas para novos festivais como o Festival da Música Popular Brasileira, realizado na década de 1960 (MARTINELLI, 2013). A partir disso, outros eventos foram criados e, de acordo com Hobsbawm (2013, p.54), os festivais "se multiplicam como coelhos. Seu número disparou desde os anos 1970 e nada sugere que esse crescimento esteja chegando ao fim".

Como podemos ver em uma pesquisa realizada pelo o Data SIM em parceria com a empresa Sympla em 2018, o Brasil é um país que abriga em média 1.928 festivais de música por ano. Para conseguir chegar a esse número, o centro de pesquisa definiu um conceito base de festivais que seriam eventos cujo conteúdo principal é a música, que em sua programação possua contratações de diversas bandas, músicos ou DJs, e, por fim, que a própria organização se identifique como um evento de festival de música. A partir disso, analisaram todo o histórico de eventos lançados na plataforma digital Sympla no período de 2016, 2017 e 2018 (DATA SIM, 2019).

Para garantir uma abrangência e validade dos resultados, a empresa mapeou também festivais publicados em outras plataformas de divulgação de eventos online e utilizaram dados fornecidos pelos produtores de eventos. É importante ressaltar que o número levantado corresponde a uma média de 50\% a $60 \%$ do número total de festivais realizados, isto se deve ao fato de alguns festivais não utilizarem as bilheterias online, que são a fonte da pesquisa.

Sendo assim, os dados utilizados para a pesquisa foram retirados de 1.792 festivais, nos quais a empresa conseguiu extrair informações importantes como

\footnotetext{
${ }^{3}$ Informação recebida em reuniões da equipe Festeja.
} 
a quantidade de pessoas que retiraram os seus ingressos e o ticket médio. Os eventos que a empresa não obteve acesso às informações foram considerados somente nas análises de sazonalidade e gênero (DATA SIM, 2019).

Os resultados destacados na pesquisa foram: (a) a maior parte dos festivais no Brasil são realizados na região sudeste; (b) os festivais ocorrem com maior frequência no segundo semestre do ano, destaque para o mês de novembro especula-se ser reflexo do ciclo orçamentário para a renúncia fiscal; (c) apresentam variedade de gênero no line-up e, (d) são pagos.

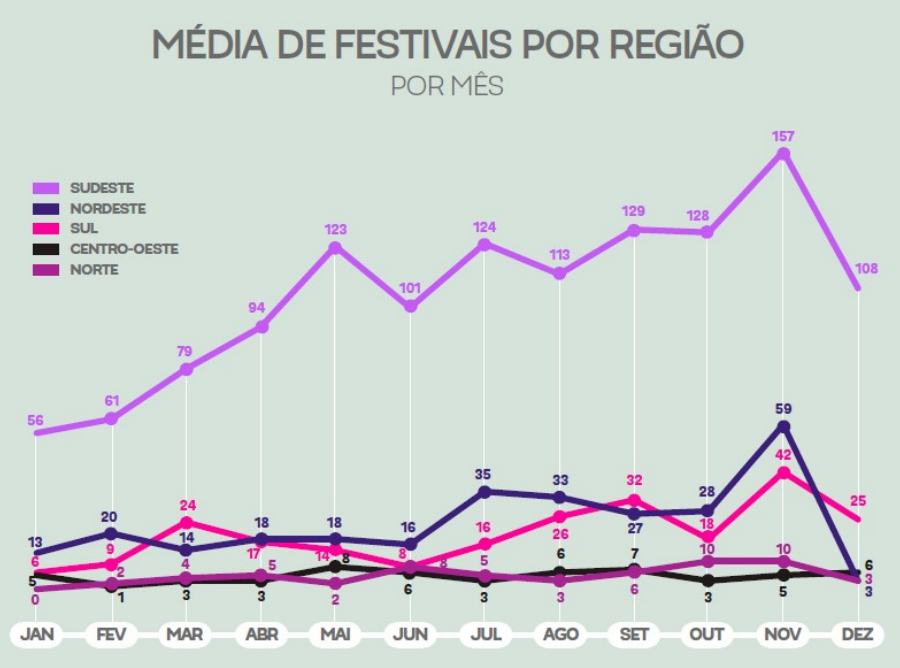

Gráfico 1: Média de festivais por região do Brasil

Fonte: Data Sim, 2019

\subsubsection{Momento atual: A pandemia do COVID-19 e suas consequências para os festivais de música no Brasil}

Com a chegada do COVID-19 o mundo se viu obrigado a realizar o distanciamento social, que são medidas que buscam restringir o convívio social de forma a evitar a propagação do vírus. Dentre essas medidas a mais comum é a paralisação de atividades e serviços não essenciais, como o comércio, festas, cinemas, academias, shows, festivais, entre outros (VIDALE, 2020). Dessa forma, o setor de eventos, cuja maior característica é a aglomeração, enfrenta grandes desafios para sobreviver durante a pandemia.

Muitos festivais tiveram as suas datas adiadas ou até mesmo canceladas para 2020. Analisando primeiramente o mercado internacional, o famoso festival Coachella, que acontece todos os anos no mês de abril, adiou a sua realização para o mês de outubro. O Tomorrowland, conhecido por ser o maior festival de 
música eletrônica do mundo, e o Ultra Music - também eletrônico - cancelaram as suas edições de 2020 (PADILHA, 2020).

No Brasil, o maior festival que aconteceria no ano de 2020, o Lollapalooza, adiou a sua edição para o mês de dezembro (Figuras 4 e 5).

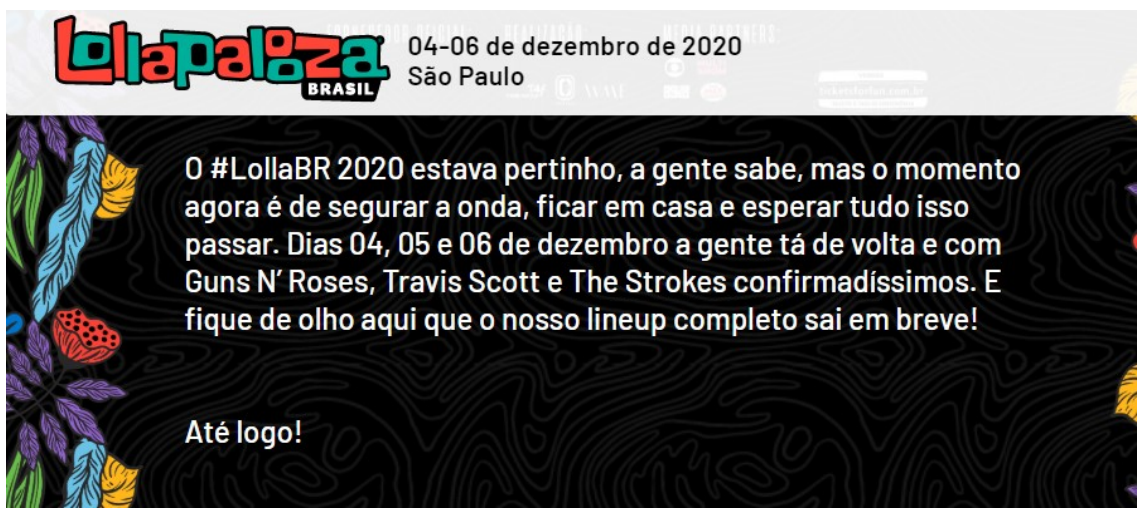

Figura 4: Comunicado do Lollapalooza

Fonte: Site oficial do Lollapalooza

\section{Lollapalooza Brasil é adiado para dezembro de 2020 por causa do coronavírus}

e Travis Scott foram confirmados no line-up do evento, em São Paulo.

Por G1

I) (1) in $\odot$

Figura 5: Adiamento do Lollapalooza na mídia

Fonte: Globo.com

No gênero sertanejo, tanto o Villa Mix (Figura 6), quanto o Buteco do Gusttavo Lima (Figura 7) adiaram as suas edições que iriam acontecer no dia 08 de abril de 2020 e 16 de maio de 2020, respectivamente. Ambos os festivais não apresentaram uma nova data, e só irão se posicionar novamente após a liberação oficial dos eventos. Anteriormente à declaração da pandemia, o 
Festeja ainda não tinha divulgado nenhuma edição para o ano, sendo assim o festival não se posicionou sobre o assunto.

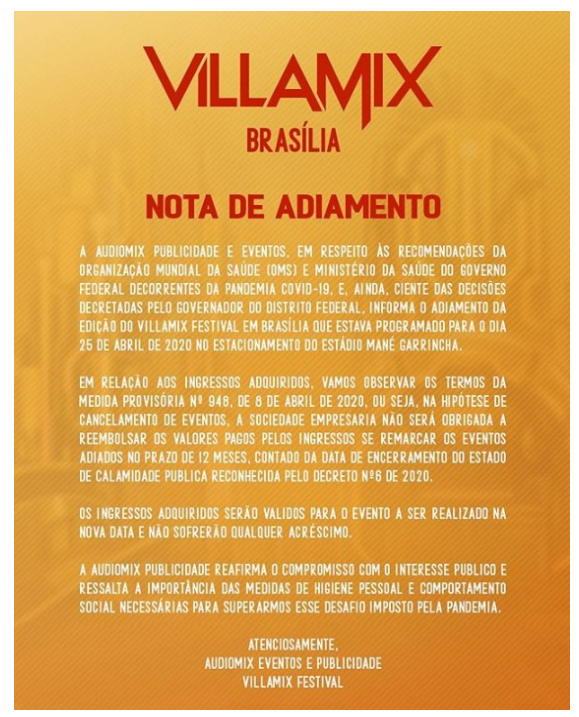

Figura 6: Nota de adiamento do VillaMix

Fonte: Reprodução/Instagram

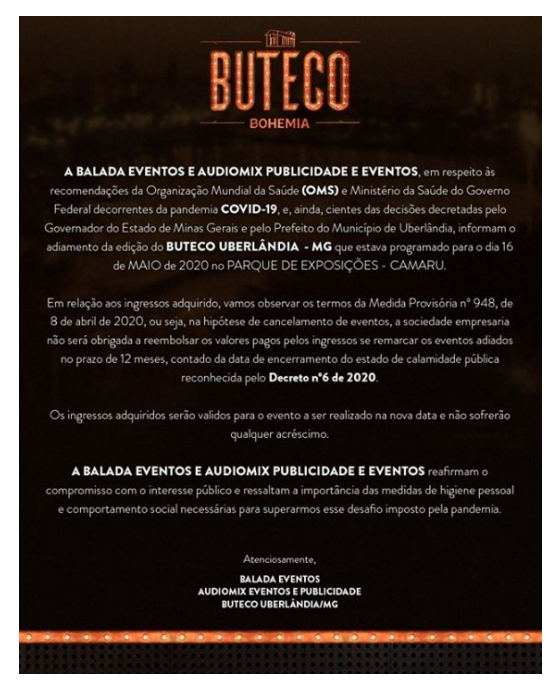

Figura 7: Nota de adiamento do Buteco

Fonte: Reprodução/Instagram

Analisando quantitativamente o impacto do COVID-19 no mercado da música no Brasil, o DATA Sim realizou um estudo com 536 empresas e microempreendedores individuais com CNPJ, e os números são impactantes (RIBAS; GOMES, 2020). De acordo com a pesquisa, há 19.996 profissionais envolvidos nas operações dessas empresas e os estados mais afetados são: São Paulo, Rio de Janeiro, Minas Gerais e Rio Grande do Sul. Sobre os 
principais impactos relatados temos os adiamentos, cancelamentos, a diminuição do ritmo de trabalho e a interrupção das atividades como as principais queixas.

Como reflexo da paralisação total das atividades com o público, a pesquisa estima que 8.141 eventos foram afetados, 8.060 .693 pessoas foram atingidas e um prejuízo financeiro estimado em $R \$ 483.214 .006,00$. Vale ressaltar que esses números são de acordo com as 536 empresas entrevistadas, caso fosse considerada a estimativa média (1.928) dos eventos por ano, podemos deduzir que o impacto do COVID-19 nos eventos é bem maior.

O mercado de eventos era um setor em ascensão antes da pandemia. Uma pesquisa realizada pelo Facebook em janeiro de 2020, apontava que até 2023 a venda de ingressos de música ao vivo mundial excederia uma receita de U\$25 bilhões de dólares, o que representa um aumento de $14 \%$ em relação a 2019. Esse aumento seria consequência dos serviços de streaming e das mídias sociais, que mudaram a forma como as pessoas consomem música, interagem com os artistas e descobrem e planejam quais shows irão assistir (FACEBOOK, 2020).

Enquanto os eventos de música ao vivo conectam as pessoas no mundo físico, grande parte da experiência em torno do show acontece digitalmente. A grande maioria (90\%) dos espectadores no Brasil dizem descobrir os eventos online, e $85 \%$ dizem gostar de saber mais sobre os próximos shows nos quais podem estrar interessados em ir também através das mídias sociais (FACEBOOK, 2020).

Ainda de acordo com a pesquisa, $81 \%$ dos espectadores no Brasil descobrem shows pelo Facebook, Instagram, Messenger ou WhatsApp, o que torna as plataformas digitais do Facebook a principal fonte de descoberta. Após as mídias sociais, os mecanismos de pesquisa, como o Google (39\%) e o Youtube $(30 \%)$ são os próximos recursos digitais mais populares que os frequentadores de shows referenciam para encontrar as próximas apresentações.

Com esse estudo pode-se perceber que anteriormente à pandemia as pessoas já recorriam mais a internet para descobrirem sobre os festivais. Em um momento onde estamos impedidos de nos relacionarmos fisicamente, e consequentemente de frequentar shows e festivais, as pessoas passaram a utilizar ainda mais as redes sociais. Em consequência do aumento dessas atividades, foi preciso inventar um novo modelo de festival para atender a esse público, os festivais onlines, ou lives, como são popularmente chamados. 


\section{Diagnóstico da situação-problema e oportunidades}

As apresentações artísticas através das lives explodiram com o avanço da pandemia. Em um momento tão sensível, onde foi necessária a implementação de diversas restrições sociais, as lives passaram a ser o como uma válvula de escape para a população, uma nova maneira de se relacionarem, e o mais importante, se divertirem.

No Brasil, tudo começou com a dupla sertaneja Mateus \& Kauan realizando um show ao vivo na rede social Instagram. A repercussão foi tanta que outros artistas começaram a estudar a ideia de também realizarem os seus shows, e aprimorarem a produção da transmissão. (DIAS, 2020d)

A plataforma escolhida pelos demais artistas foi o YouTube. Um site de cultura participativa, que permite aos seus usuários criarem seus próprios conteúdos, sem limite de uploads e de fácil acesso. O maior aglutinador de mídia de massa da internet no início do século 21, o YouTube conseguiu definitivamente transformar a maneira como as pessoas consomem conteúdo e é uma força a ser levada em consideração no contexto do marketing digital (BURGESS, 2009).

\subsection{Lives e YouTube}

As lives não só chamaram atenção dos telespectadores, mas também das marcas. Com a gigantesca visualização dos shows transmitidos pelo YouTube, o mercado publicitário encontrou nas lives uma oportunidade de um novo modelo de negócio.

Os valores cobrados de publicidade podem chegar a números exorbitantes, de dez mil a quinhentos mil reais. De acordo com o colunista Leo Dias, do Uol, Wesley Safadão cobrou $\mathrm{R} \$ 100$ mil por uma simples inserção de marca, enquanto os números de Marília Mendonça chegam a $\mathrm{R} \$ 500$ mil (DIAS, 2020e).

Como tudo na internet se propaga muito rápido e toma dimensões muito maiores, as propagandas realizadas pelos os artistas durante as lives, como o consumo de bebidas alcóolicas de patrocinadores e a exposição excessiva de marcas, passaram a ser realizadas de forma irresponsável, violando diversas 
regras do YoutTube (YOUTUBE, 2020). A plataforma precisou então, entrar em contato com escritórios, gravadoras e artistas para relembrarem tais regras, que antes do período de isolamento social não eram rigorosamente cobradas.

Após este comunicado, as novas lives precisam seguir à risca as regras contratuais da plataforma, caso contrário podem ter as suas transmissões derrubadas. Por conta disso, artistas estão considerando terem suas próprias plataformas para melhor administrar a receita advinda das transmissões onlines (DIAS, 2020c).

\subsection{As maiores lives do YouTube são brasileiras}

O primeiro artista a agarrar de fato essa nova oportunidade de mercado foi Gusttavo Lima. No dia 28 de março de 2020, Gusttavo resolveu transmitir o seu festival "Buteco em casa" pelo YouTube e conseguiu atingir números jamais vistos antes. O cantor quebrou o recorde de visualizações simultâneas da plataforma - que antes pertencia a uma apresentação da cantora Beyonce no festival Coachella 2018 - batendo 731 mil visualizações, performou durante cinco horas ininterruptas, foi o artista que ganhou mais seguidores no Instagram em um dia - mais de 1 milhão - e foi o assunto mais falado do Twitter no Brasil (Figura 8) (DIAS, 2020f).

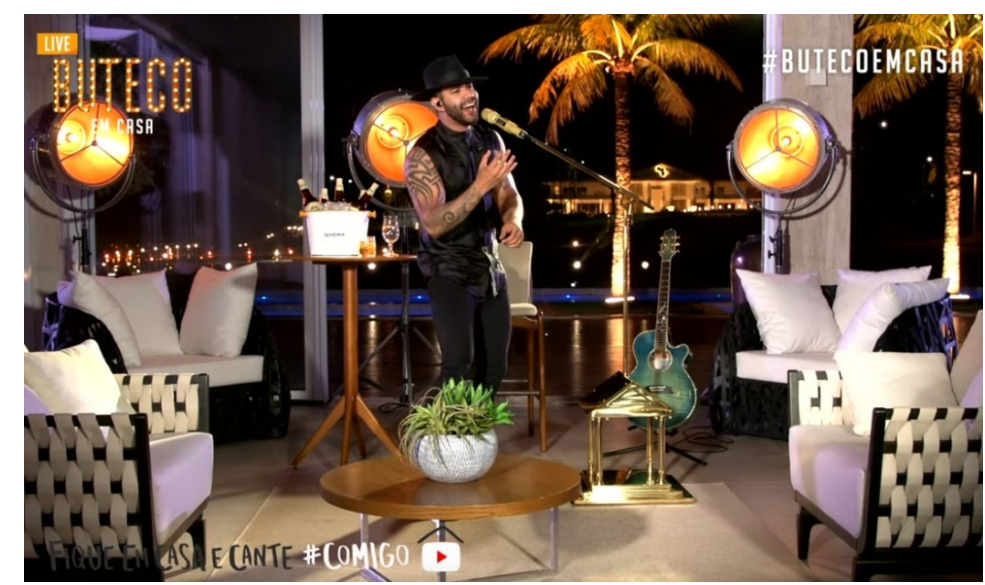

Figura 8: Live do Gusttavo Lima

Fonte: Reprodução/Youtube

Além disso, uma atitude que chamou bastante atenção do público foram os pedidos de doações que ocorreram para as pessoas que estão passando 
necessidade com a pandemia. Durante toda a sua apresentação foram arrecadados mais de $\mathrm{R} \$ 100$ mil e dezenas de toneladas de alimentos e álcool gel, que juntos equivalem a $\mathrm{R} \$ 500$ mil. As doações realmente foram um diferencial, e a sua iniciativa conseguiu influenciar outros artistas a fazerem o mesmo (Jornal de Brasília, 2020).

Seguindo a mesma linha, foi a hora dos fãs da dupla Jorge \& Mateus lotarem a internet com pedidos de uma live dos cantores e no dia 31 de março a vontade dos fãs foi atendida (DIAS, 2020a). Se antes Gusttavo Lima já havia batido recordes a dupla por sua vez conseguiu triplicar esses números (Figura 9).

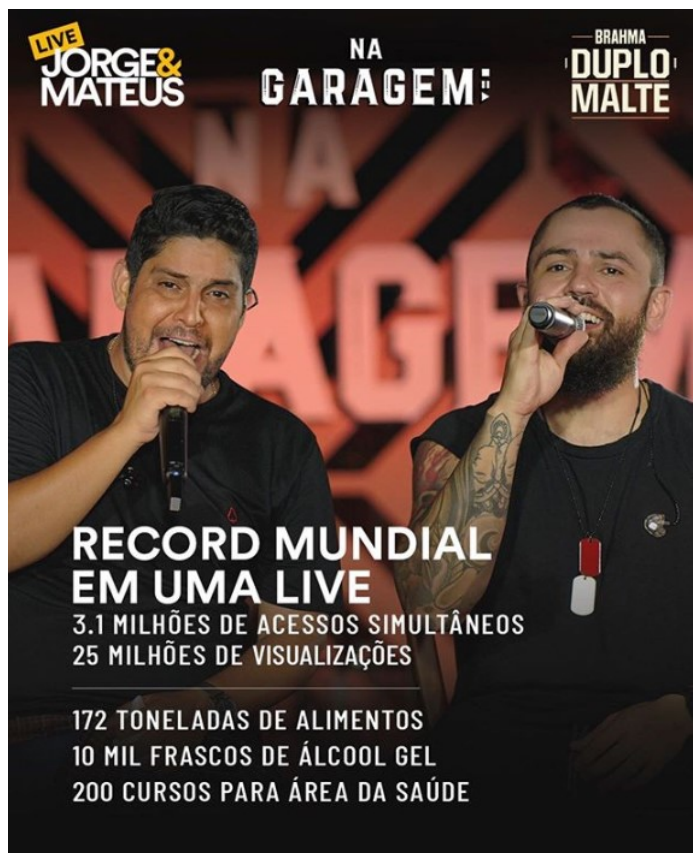

Figura 9: Resultado Jorge \& Mateus

Fonte: Reprodução/Instagram

Como divulgado na conta do Instagram dos artistas, a live que teve 4:30hr de duração conseguiu bater 3,1 milhões de acessos simultâneos e recolher inúmeras doações. Com isso, os cantores sertanejos quebraram o recorde mundial de visualizações que antes pertencia a Gusttavo Lima.

A partir desse momento começou-se então uma competição entre os artistas para ver quem iria fazer a live mais bem produzida, com mais visualizações e claro, com mais patrocinadores. Foi então que Marília Mendonça, mais conhecida pelos brasileiros como a "Rainha da Sofrência", ditou uma nova maneira de lidar com a situação e decidiu fazer uma live mais simples, 
com produção reduzida e principalmente com menos pessoas envolvidas (DIAS, 2020b).

Com essa nova receita, atrelado ao sucesso da cantora, Marília Mendonça conseguiu bater o recorde da dupla Jorge \& Mateus e hoje é a pessoa com mais acessos simultâneos (3,3 milhões) (SOM LIVRE, 2020) em uma live do Youtube.

A repercussão de seu show foi tamanha que chamou a atenção da mídia internacional. O jornal norte-americano "The New Tork Times" publicou uma matéria sobre o sucesso das lives sertanejas no Brasil - que dominam sete posições das dez mais assistidas do YouTube - e deu destaque para a cantora que lidera o ranking de acessos simultâneos (Figura 10).

Ehe Niew tlork שimes

How Housebound Brazil

Popstars and CEOs Caught

Streaming Mania and

Dominated YouTube

\begin{abstract}
By Reuters
April 29, 2020

SAO PAULO - "Calling all the cattle! Our live broadcast is about to begin," Brazilian singer Marilia Mendonca whooped as she kicked off a recent three-and-a-half-hour quarantine performance of 'sertanejo' country music hits from her living room, streamed on YouTube.

The concert, which drew 3.3 million peak concurrent viewers - a worldwide record for YouTube - was one of the most dramatic signs yet of how live streaming has gone viral in Brazil as the coronavirus lockdown has virtually paralyzed Latin America's most populous country. It was also just the culmination of a single webcast-filled day that saw everyone from CEOs to government ministers holding forth from their home offices and living rooms.
\end{abstract}

Figura 10: Marília Mendonça ganha destaque no jornal "The New York Times"

Fonte: Reprodução The New York Times.

Além do número de acessos gigantesco, a cantora conseguiu também uma boa quantia de arrecadação de alimentos e produtos de limpeza 
(OLIVEIRA, 2020). Porém, o que chamou mesmo a atenção do público foi a presença de um intérprete de libras (como pode ser visto no canto inferior direito da Figura 13) que traduzia todas as canções da artista simultaneamente. Após essa iniciativa, demais artistas passaram a adotar essa ferramenta em suas transmissões. (LORENTZ, 2020).

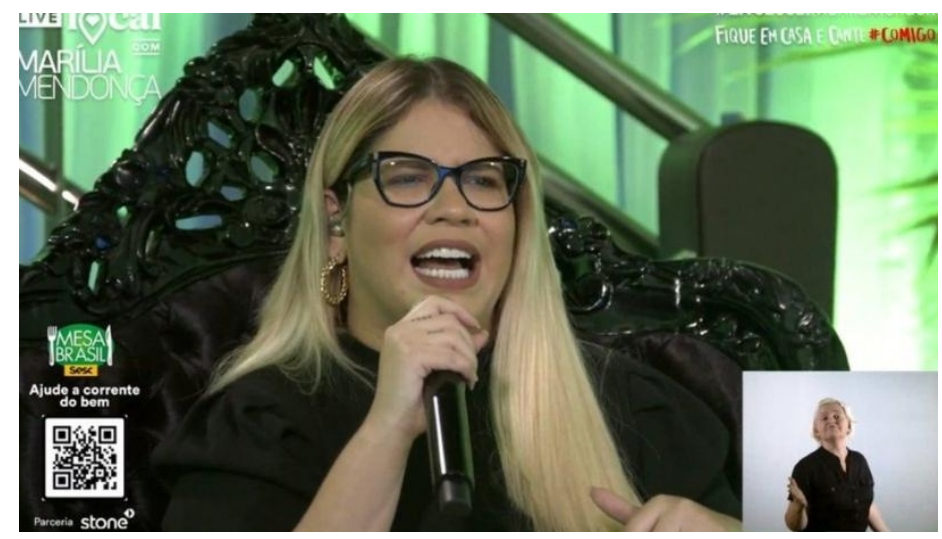

Figura 11: Live Marília Mendonça

Fonte: Reprodução/Youtube/ Marília Mendonça 


\section{Passos metodológicos}

Esta pesquisa é caracterizada como exploratória posto que visa proporcionar maior familiaridade com o problema, abrangendo levantamento bibliográfico e entrevistas com pessoas envolvidas no problema pesquisado (Gil, 2008). Foi realizada em três estágios: No primeiro estágio foram consultados dados secundários sob forma de artigos, relatórios do setor, reportagens de fontes confiáveis e vídeos no YouTube. Esta fase permitiu um maior conhecimento do setor e seus atuais desafios além de embasar 0 desenvolvimento dos próximos passos da pesquisa. No segundo estágio, foi realizada uma entrevista com a equipe responsável pelo Festeja. No terceiro estágio foi realizada uma pesquisa com o público de lives do setor através de um questionário online. Os três estágios da pesquisa estão detalhados a seguir.

\subsection{Pesquisa com dados secundários}

A primeira fase da pesquisa consiste na análise dos dados disponibilizados pela gravadora Som Livre, juntamente com a coleta de conteúdos publicados em veículos de comunicação, livros e artigos científicos sobre o tema estudado. $O$ objetivo dessa fase foi entender como o mercado tem se comportado com o novo modelo de negócios dos shows e festivais ao vivo. Os relatórios da Som Livre são disponibilizados apenas para consultas internas da equipe, mas os dados relevantes para esta pesquisa são de acesso público. Esta fase da pesquisa embasou os capítulos dois e três, respectivamente: contexto e realidade investigada, diagnóstico da situação-problema e oportunidades.

\subsection{Pesquisa com dados primários}

A segunda fase da pesquisa consiste na análise dos dados coletados através de entrevistas com a equipe responsável pela a produção do Festival Festeja. O objetivo dessas entrevistas foi entender como festival estaria se posicionamento durante a pandemia e prospectar o seu futuro. O roteiro da entrevista encontra-se no Anexo 1. As respostas foram obtidas por e-mail, dado que vivemos num momento de distanciamento social. 
A terceira fase da pesquisa foi realizada através de um questionário elaborado via Google Forms e enviado por redes sociais. Primeiramente foi enviado para uma amostra de acessibilidade e posteriormente foi usado a "bola de neve" onde um respondente indicava outros. No total foram obtidas 63 respostas válidas. O questionário encontra-se no Anexo 2.

A pesquisa teve como intuito entender o comportamento do público que consumiu as lives de sertanejo nos últimos meses. 


\section{Análise dos resultados}

Esta análise será organizada em duas seções. A primeira refere-se às entrevistas realizadas com a equipe do Festeja e a segunda apresenta os resultados da pesquisa com o público. No Capítulo 6 (Discussões e propostas) os resultados das pesquisas serão confrontados para a elaboração de propostas.

\subsection{Entrevista com a equipe do Festeja}

Nesta primeira etapa foram realizadas entrevistas com os produtores responsáveis do Festeja. Para manter a identidade dos entrevistados, os nomes foram trocados (Anexo 1).

\subsubsection{Entrevista com Mariana}

A primeira entrevista foi realizada com a produtora Mariana. Funcionária da empresa Som Livre há cinco anos, Mariana é formada em administração de empresas e é uma das responsáveis pela produção do Festival Festeja.

Ela afirma que diante do novo cenário, a equipe já estava esperando por mudanças. A decisão mais difícil foi o adiamento total do festival no ano, uma vez que o festival conta com um público de no mínimo de 10 mil pessoas, sendo inviável a realização do mesmo nesse momento.

Assim que a decisão foi tomada, a equipe toda foi informada e, a partir disso, começou-se um processo para "reinventar" o modelo de negócio adequando ao momento, se adaptando ao novo universo. A ideia é estar presente nas redes sociais com conteúdos diversos e na TV com imagens inéditas de eventos passados. Fazendo com que o público mantenha o contato com o festival.

Em relação ao posicionamento perante o público, como o Festeja ainda não tinha nenhuma data divulgada para esse ano, a produção do festival optou por não realizar um comunicado específico e direto. Como dito anteriormente, o público tem interações com a marca pelas redes sociais e TVs e, de acordo com 
Mariana, dessa forma o festival se mantém presente e "de maneira orgânica" o recado é dado.

Para a retomada do festival a produtora ressalta que hoje já estão com a programação pronta. A ideia é manter o que haveria esse ano para o próximo. Porém, sem nada muito definido, pois ainda estão aguardando como serão apresentados os novos cenários.

Por fim, Mariana acredita que o mercado irá mudar completamente. A interação do público com os grandes eventos nunca mais será a mesma e nem dos eventos com o público. A responsabilidade social estará muito mais presente, assim como a responsabilidade ambiental.

\subsubsection{Entrevista com Rafael}

Rafael trabalha na Som Livre há três anos e atualmente é o coordenador da área de shows e festivais da empresa. Quando questionado sobre o cancelamento do Festeja para 2020, Rafael diz que foi a decisão mais difícil que precisou tomar na companhia, mas que por ter uma equipe muito bem alinhada e preparada a situação foi conduzida de forma tranquila.

Com a decisão do cancelamento do festival eles precisaram começar a pensar em novas alternativas de negócio. Optaram por aumentar as suas interações nas mídias sociais e aproveitar a sua relação direta com a TV Globo para reprisarem edições passadas do Festeja na TV e nas redes associadas.

Em relação ao público, Rafael também ressalta que não houve nenhum comunicado direto, pois como ainda não tinham divulgado nenhuma data do festival não precisariam passar nenhuma instrução para os consumidores.

Para a retomada do festival o coordenador se mostra esperançoso, e diz que em 2021 irá fazer o que foi planejado para esse ano, realizando apenas algumas modificações por conta das normas de segurança sanitária.

Por fim, em relação à perspectiva do mercado, Rafael acredita que tanto os artistas/produtores, como o público irão de certa forma mudar a forma de consumo e passarão a ser ainda mais seletivos em quais eventos irão. 


\subsection{Resultado da pesquisa com o público que assistiu lives de sertanejo no último mês}

Nesta fase da pesquisa foi realizado um questionário elaborado via Google Forms (Anexo 2). As respostas dessa fase foram transferidas para uma planilha de Excel, organizadas em gráficos e tabelas para melhor análise.

A pesquisa foi realizada com 63 entrevistados, cujas faixas etárias se distribuem em: 35 pessoas entre 19 - 24 anos, 17 entre 25 - 29 anos, 9 entre 30 34 anos, e 2 entre 40 anos ou mais (Gráfico 01).

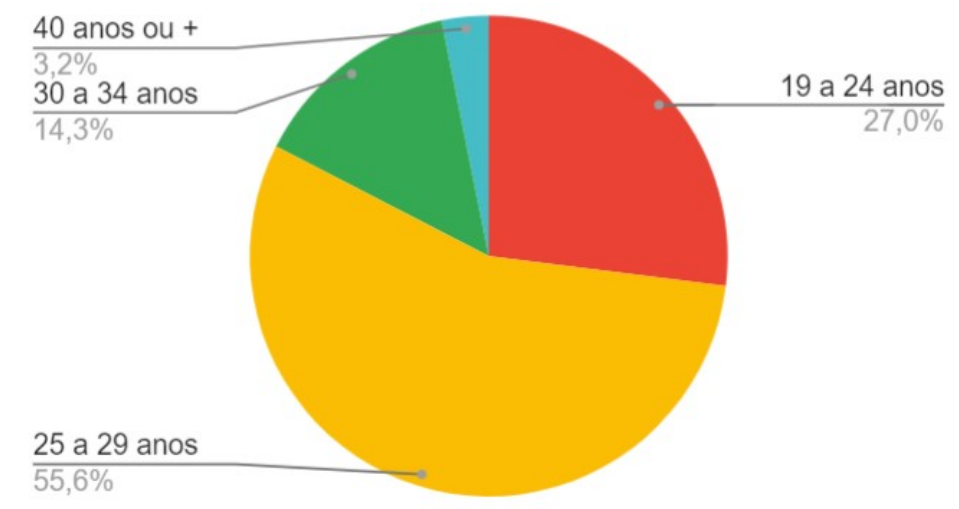

\section{Gráfico 2: Faixa etária dos entrevistados}

Fonte: Elaborada pelo autor

Dentro da amostra efetuada, 82,5\% afirmam terem assistido a alguma live sertaneja, enquanto que os outros 11 entrevistados afirmam não terem assistido a nenhuma. Todas as respostas foram consideradas, posto que nas perguntas subsequentes os respondentes poderiam acrescentar artistas cujas lives assistiu, e as respostas são relevantes para esta pesquisa.

Quando perguntado aos entrevistados quais lives eles teriam assistido as mais mencionadas foram, em ordem: Jorge \& Mateus $(80,45 \%)$, Marília Mendonça (75\%), Gusttavo Lima (58,9\%), Zé Neto \& Cristiano (42,9\%), Bruno \& Marrone (39,3\%) e Luan Santana $(39,3 \%)$. 


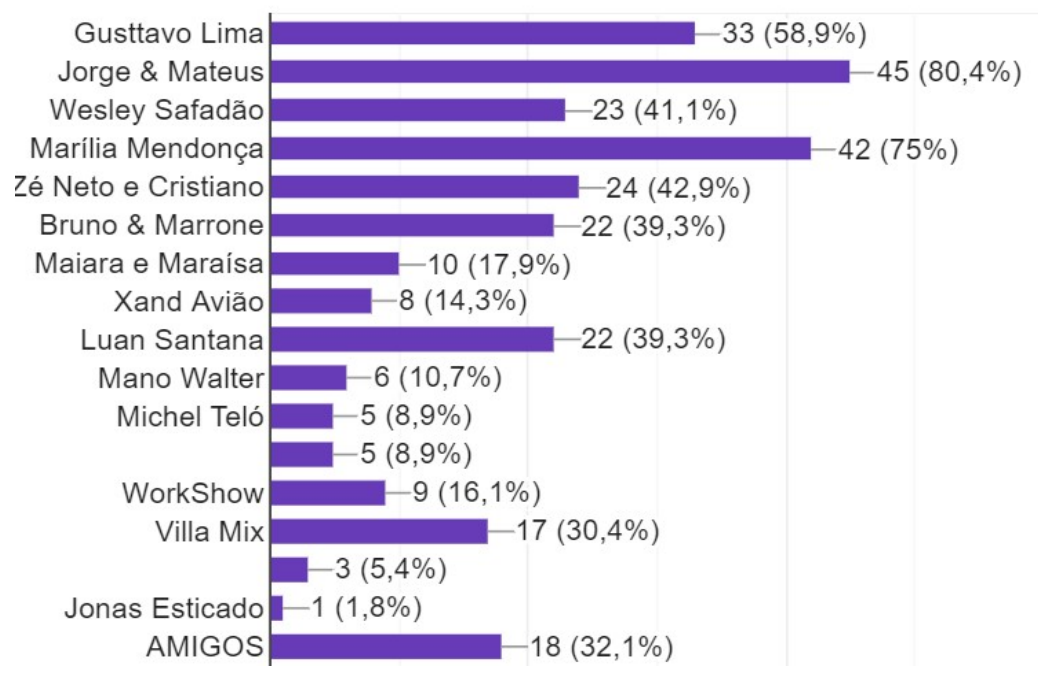

Gráfico 3: Lives assistidas pela amostra

Fonte: Elaborada pelo autor

Em relação às preferências dos entrevistados (Gráfico 04), a live da Marília Mendonça $(29,1 \%)$ aparece como a preferida do público, em seguida Jorge \& Mateus (20\%) e Gustavo Lima (14,5\%) em uma amostra de 55 pessoas. Em contrapartida, quando perguntado sobre a live que tenha menos gostado, uma amostra de 48 pessoas respondeu em primeiro lugar Luan Santana $(18,8 \%)$, em segundo Marília Mendonça $(14,6 \%)$ e em terceiro Maira \& Maraisa $(6,3 \%)$.

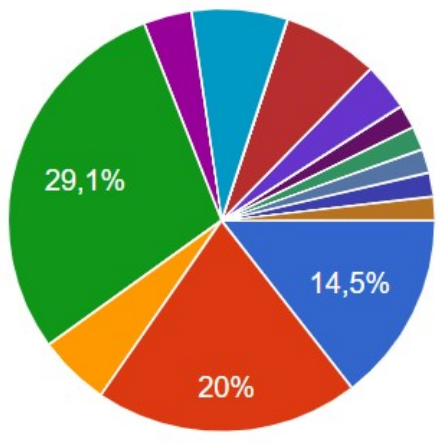

Gráfico 4: Lives que mais agradaram o público

Fonte: Elaborada pelo autor 


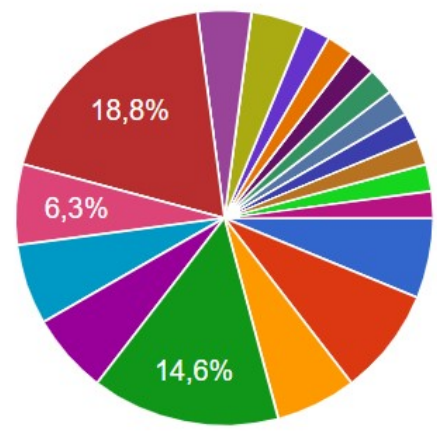

Gráfico 5: Lives que menos agradaram o público

Fonte: Elaborada pelo autor

No que diz respeito ao meio de comunicação utilizado para a busca de informações sobre as lives, $88,5 \%$ dos entrevistados afirmam utilizar a rede social Instagram, em seguida o "boca a boca" entre as pessoas $(32,8 \%)$ e em terceiro lugar o WhatsApp (29,5\%).

Foi perguntado também, se após o período de isolamento social os entrevistados continuariam assistindo as lives. Os resultados (Gráfico 6) mostram que as pessoas estão sim mais propícias a continuarem assistindo as transmissões, o que nos leva a próxima pergunta. O que motiva o público a continuar assistindo as transmissões pós pandemia?

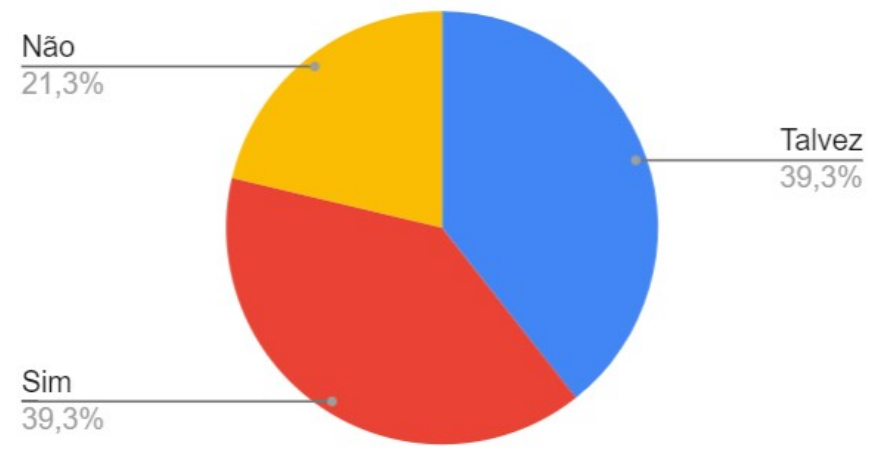

Gráfico 6: Continuar assistindo lives pós pandemia

Fonte: Elaborada pelo autor

Dentre as 41 respostas que foram obtidas com essa pergunta, as que apareceram com mais frequência foram: (a) "Show de graça"; (b) "Conforto de casa"; (c) "Entretenimento de qualidade". Em seguida, foi abordada uma 
possível cobrança para o acesso do conteúdo das lives. Em uma amostra de 56 pessoas, $87,5 \%$ não pagariam, enquanto $12,5 \%$ aceitariam pagar pelo conteúdo.

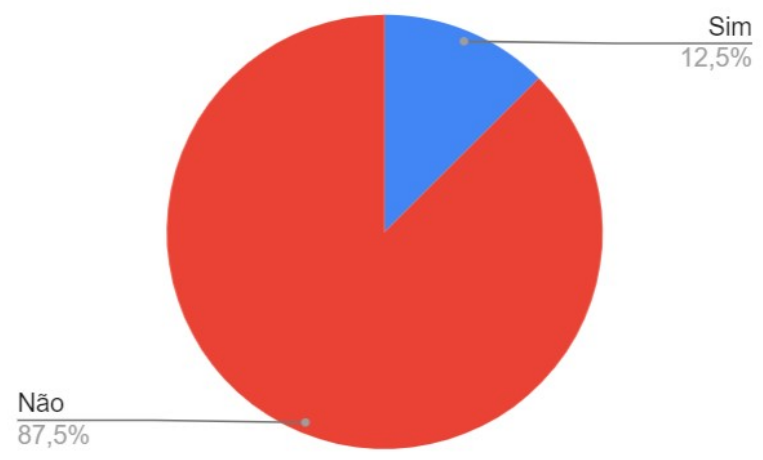

Gráfico 7: Aceitar pagar por uma live

Fonte: Elaborada pelo autor

Outro ponto muito importante da pesquisa diz respeito ao tempo em que o público se sentirá confortável em voltar a frequentar eventos ao vivo. Os números são bastante interessantes: enquanto $39,1 \%$ diz que voltaria a frequentar os eventos de imediato e $21,9 \%$ teriam dúvidas, outros $39,1 \%$ optam por não voltar. Da amostra de pessoas que responderam "Não", 67,4\% diz que só irá voltar quando se sentir totalmente seguro.

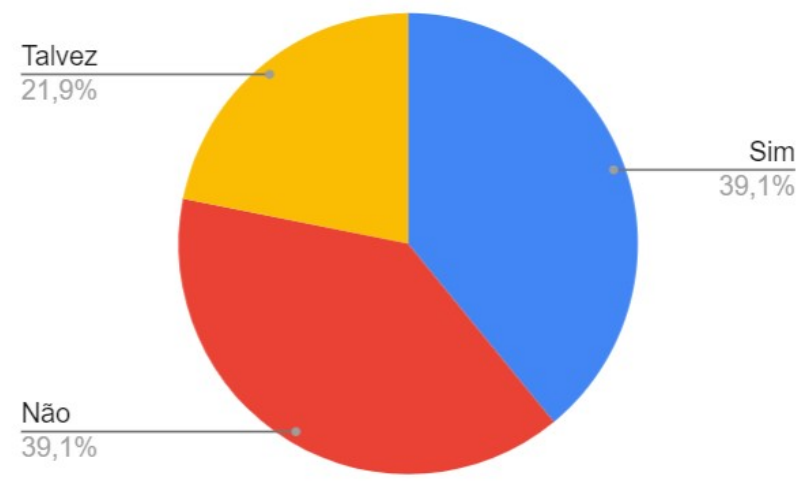

Gráfico 8: Voltar a frequentar eventos de imediato

Fonte: Elaborada pelo autor

Por fim, as últimas duas perguntas do questionário foram relacionadas à percepção do consumidor. Ao serem questionados se recordavam de alguma marca relacionada às lives, a cerveja Brahma Duplo Malte obteve 48,14\% das menções. Em seguida, foram questionados se passaram a consumir alguma 
marca por influência das lives, e novamente a cerveja Brahma Duplo Malte foi destaque $(8,8 \%)$, sendo a única marca mencionada pelo público.

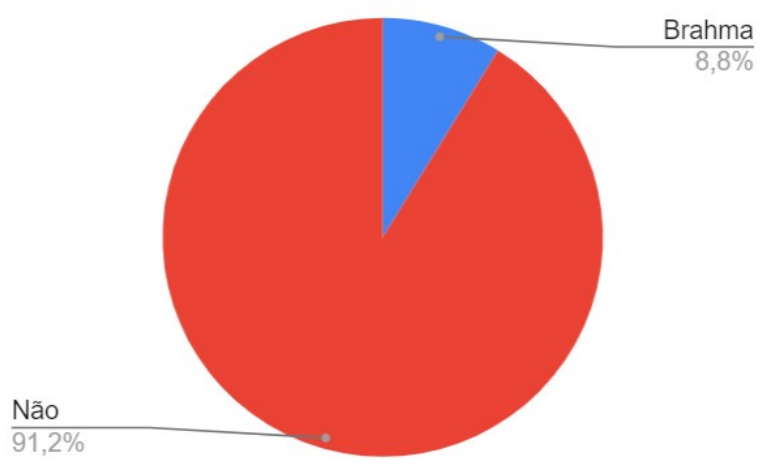

Gráfico 9: Marcas que passaram a ser consumidas

Fonte: Elaborada pelo autor 


\section{Discussões e propostas}

Neste capítulo serão confrontados os resultados da pesquisa de dados secundários e primários para o desenvolvimento de propostas.

\subsection{A retomada do setor de música ao vivo}

Hoje não temos como prever nem quando e nem como vamos sair do momento de isolamento social e considerar a retomada do setor. Os grandes eventos foram adiados e até o momento não possuem uma data certa de volta. Especula-se que a liberação só aconteça em 2021, mas tudo depende da legislação local autorizar o setor a operar.

Mesmo vivendo em um momento de incertezas, de acordo com as pesquisas realizadas, serão necessários novos protocolos de segurança para a retomada dos eventos ao vivo. Tais protocolos irão variar desde o número específico de público autorizado por evento, aos locais de realização ambientes arejados - até de medidas sanitárias, como a disponibilização de álcool em gel $70 \%$ em áreas de circulação.

A retomada será um grande desafio para os produtores de eventos. Além dos novos protocolos de segurança que terão que adotar, eles precisarão convencer a sua principal fonte de receita a voltar a frequentar os eventos: o público. Como visto ao longo do trabalho, grande parte do público afirma que só irá voltar a frequentar esse tipo de evento quando se sentirem $100 \%$ seguros. Outra questão de grande impacto é a queda da renda da população durante a quarentena. Sendo assim, podemos esperar um choque de comportamento do consumidor, com novos hábitos e mais criteriosos na hora da escolha do evento.

\subsection{O futuro das lives}

Impossibilitados de frequentar eventos ao vivo, as lives se tornaram para o público o melhor e mais seguro entretenimento. Para os artistas, foi a melhor maneira de manter o contato com o público, arrecadar doações, e principalmente gerar receita através de patrocínio. 
Em meio a tantas dúvidas provocadas pelo momento em que vivemos, e a incerteza da volta, os artistas e produtores passaram a cogitar um novo modelo de negócio para o curto e o longo prazo. A cobrança de ingresso para o acesso das lives. Entretanto, de acordo com os entrevistados desse estudo, 87,5\% não pagaria por esse tipo de conteúdo.

"Eu acho que o ponto legal da live é se conectar com os amigos mesmo estando longe. Todo mundo assistindo a mesma live e conversando sobre. Quando acabar a quarentena, vamos poder voltar a se conectar de outras formas."

"Se for para pagar eu prefiro ir a um show presencial."

Desde então, as lives se tornaram parte da rotina da população, mas como podemos perceber através dos relatórios disponibilizados para esse estudo, a audiência das transmissões está em declínio. Acredita-se que o ser humano irá valorizar ainda mais o convívio e a interação social depois desse isolamento compulsório. Sendo assim, adicionar uma cobrança extra sem uma estratégia pode ser a decadência das lives.

\subsection{Alternativas para profissionais do mercado de eventos}

Impedidos de realizarem eventos, os profissionais precisaram se reinventar, criando novos modelos de negócio. Poucos obtiveram sucesso, e infelizmente estão ocorrendo demissões em massa no setor.

A primeira alternativa encontrada pelos profissionais da área foram as transmissões dos shows ao vivo, e não há dúvida de que foi produto de entretenimento mais consumido durante a quarentena. Quando estrearam, os shows online excediam marcas de três milhões de visualizações simultâneas e batiam recorder mundiais.

Hoje, justamente pelo o seu excesso e pela diversidade de lives realizadas no mesmo dia, pode-se perceber uma redução significativa da audiência. Com isso, os produtores precisaram novamente encontrar um novo tipo de entretenimento para suprir a necessidade do público, o que nos leva a volta dos drive-ins.

Os cinemas drive-ins, que faziam muito sucesso em tempos passados, voltaram a ter visibilidade com a impossibilidade da população de frequentar as tradicionais salas de cinema. Além de filmes, produtores estão adaptando a 
estrutura dos drive-in para servirem como casa de shows. A iniciativa começou na Dinamarca, e o novo modelo de negócio já está sendo implementado nas cidades de Brasília, São Paulo e Rio de Janeiro.

\subsection{Eventos híbridos}

A tecnologia vem afetando integralmente a forma como nos comunicamos, trabalhamos e socializamos. Durante o distanciamento social a tecnologia passou a ser ainda mais necessária para a população.

Os eventos digitais se tornaram a única forma de socialização, e principalmente o único meio dos profissionais de eventos gerarem receitas. Em médio prazo, essa transformação no hábito do consumidor pode ser benéfica para os produtores, e o conceito de eventos híbridos - que são eventos que acontecem parte presencial e parte virtual - podem começar a ganhar força.

Com os eventos híbridos há a possibilidade dos produtores em potencializar vários dos seus segmentos. O seu público pode aumentar consideravelmente com a venda de ingressos presenciais e virtuais, e abrem-se portas para novos negócios, como a possibilidade de diferentes formas de captação de patrocínios.

Como podemos ver na entrevista com a equipe do Festeja, eles já observam a mudança no hábito do consumidor e acreditam que após o fim da quarentena a interação do público com os grandes eventos nunca mais será a mesma e nem dos eventos com o público. Com isso, a implementação do modelo de evento híbrido pode ser uma grande oportunidade para o Festival crescer e ser o pioneiro de um novo negócio.

A Tabela 1 apresenta um resumo das possibilidades futuras para o mercado de eventos de música de acordo com os resultados da pesquisa. 
Tabela 1 Sumário das propostas

\begin{tabular}{|c|c|}
\hline dos da pesquisa & es \\
\hline $\begin{array}{l}\text { Produtores de festivais tendem a } \\
\text { manter a programação para a } \\
\text { retomada (mesmo line-up). }\end{array}$ & $\begin{array}{l}\text { Durante a pandemia a maioria dos } \\
\text { artistas investiu no relacionamento com } \\
\text { os fãs nas redes sociais. Planejar um } \\
\text { melhor aproveitamento deste } \\
\text { relacionamento. }\end{array}$ \\
\hline $\begin{array}{l}\text { Mudança no mercado e na relação } \\
\text { com o público. }\end{array}$ & 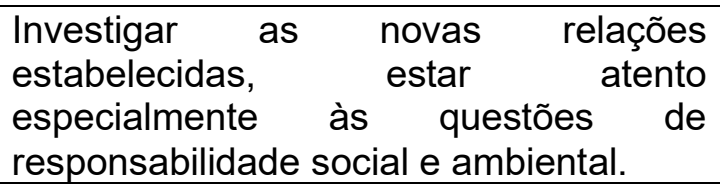 \\
\hline $\begin{array}{l}\text { Público aberto à novas formas de } \\
\text { consumo. }\end{array}$ & $\begin{array}{l}\text { Investigar a "nova jornada } \\
\text { consumidor" no novo cenário para } \\
\text { desenvolver novas experiências de } \\
\text { consumo. }\end{array}$ \\
\hline $\begin{array}{l}\text { Formas de comunicação mais } \\
\text { usadas: Instagram, Whatsapp e "boca } \\
\text { a boca", muitas vezes combinados e } \\
\text { relacionados. }\end{array}$ & $\begin{array}{l}\text { Investir em experiências digitais } \\
\text { integradas para facilitar esta } \\
\text { comunicação consumidor - consumidor. }\end{array}$ \\
\hline $\begin{array}{l}\text { Pouca aceitação à lives pagas, } \\
\text { visibilidade dos patrocinadores nas } \\
\text { lives. }\end{array}$ & $\begin{array}{l}\text { Buscar novas formas de financiamento } \\
\text { através de patrocínios de experiências } \\
\text { digitais. }\end{array}$ \\
\hline $\begin{array}{l}\text { Maior parte do público só retorna } \\
\text { quando se sentir } 100 \% \text { seguros. }\end{array}$ & $\begin{array}{l}\text { Investir em procedimentos de segurança } \\
\text { e sua comunicação com o público. } \\
\text { Novos formatos de experiência como o } \\
\text { drive-in. }\end{array}$ \\
\hline $\begin{array}{l}\text { Tecnologia mais presente } \\
\text { diversos perfis de público }\end{array}$ & $\begin{array}{l}\text { Explorar novos formatos de eventos } \\
\text { híbridos. }\end{array}$ \\
\hline
\end{tabular}




\section{Conclusão}

Esta pesquisa se propôs a investigar possibilidades para o mercado de eventos de música, diante dos desafios enfrentados no momento de pandemia, tendo como objeto de estudo o Festival Festeja. Para isso, foi realizada uma pesquisa caracterizada como exploratória, feita em três estágios: No primeiro estágio foram consultados dados secundários. No segundo estágio, foi realizada uma entrevista com a equipe responsável pelo Festeja. No terceiro estágio foi realizada uma pesquisa com público de lives do setor. A partir desses dados, tornou-se possível chegar a algumas conclusões sobre a perspectiva do mercado de eventos de música.

Foi possível perceber que a retomada do setor será um grande desafio para os produtores. Atualmente ainda não há uma data certa para a volta, e tudo depende da legislação local autorizar a operação, juntamente com a criação dos novos protocolos de segurança. Além disso, o público mostra estar duvidoso em frequentar ambientes de aglomeração e grande parte afirma que só irá retornar quando se sentirem totalmente seguros.

O setor criativo foi um dos mais afetados com a pandemia e busca caminhos para o retorno. Como forma de subsistirem, artistas e produtores de eventos precisaram encontrar novos meios de gerarem receita e inicialmente foi através das lives que isso se tornou possível. As lives foram um verdadeiro sucesso no Brasil, quebraram recordes de visualizações e o mais importante de tudo, arrecadaram inúmeras doações para as pessoas que precisaram de ajuda durante esse período.

Todavia, como tudo na internet acontece muito rápido, é importante ressaltar que as transmissões sofreram uma queda de audiência e os produtores novamente precisaram se reinventar. Depois das lives, os cinemas drive-ins, que eram famosos no passado, voltaram a ganhar visibilidade e também foram adaptados para servirem como casas de shows. O novo modelo de negócio já está sendo implementado nas cidades de Brasília, São Paulo e Rio de Janeiro.

Outro ponto de atenção refere-se à mudança de comportamento do consumidor. Acredita-se que após esse período os consumidores estarão ainda mais exigentes, e criteriosos na escolha de um evento. Além do medo da 
contaminação da doença, pode-se esperar um público com uma renda mais baixa devido às demissões em massa, e as reduções salariais. Tais fatores contribuem muito para o êxito dos eventos híbridos, onde se há uma parcela do público presente fisicamente e outra parte virtualmente.

Por fim, como os eventos digitais se tornaram a principal forma de socialização da população durante a quarentena, recomenda-se que a equipe do Festeja estude a melhor maneira de aproveitar este público que foi formado durante o período de isolamento social através das plataformas de transmissão online, para proporcionar uma experiência hibrida quando for possível retomar os shows ao vivo. Resta aguardar o desenrolar dos acontecimentos para melhor ajustar os planos do setor. 


\section{Referências}

BURGESS, J. YouTube e a Revolução Digital : como o maior fenômeno da cultura participativa transformou a mídia e a sociedade. São Paulo: Aleph, 2009.

DATA SIM. Mapa dos Festivais do Brasil. São Paulo 2019. Disponível em: $<$ https://datasim.info/mapeamentos/disponivel-o-mapa-dos-festivais-do-brasil-bysympla-e-data-sim/> Acesso em: 15 de abril. 2020

DIAS, Leo. Após pedidos pela internet, Jorge \& Mateus marcam data de live-show para fãs. UOL, 31 de mar. 2020a. Disponível em: $<$ https://tvefamosos.uol.com.br/colunas/leo-dias/2020/03/31/apos-pedidos-pelainternet-jorge--mateus-marcam-data-de-live-show-pra-fas.htm> Acesso em: 31 de março. 2020.

DIAS, Leo. Live de Marília Mendonça vai ditar nova forma de fazer transmissão ao vivo. UOL, 07 de abr. 2020b. Disponível em: $<$ https://tvefamosos.uol.com.br/colunas/leo-dias/2020/04/07/live-de-mariliamendonca-vai-ditar-nova-forma-de-fazer-transmissao-ao-vivo.htm> Acesso em: 08 de abril. 2020.

DIAS, Leo. Para não depender do Youtube, sertanejos criam app para exibir shows. UOL, 20 de abr. 2020c. Disponível em: $<$ https://tvefamosos.uol.com.br/colunas/leo-dias/2020/04/20/para-naodepender-do-youtube-gusttavo-lima-criara-app-para-exibirshows.htm>. Acesso em: 12 Jun. 2020.

DIAS, Leo. Por conta do coronavírus, Matheus e Kauan farão show virtual para fãs. UOL, 17 de mar. 2020d. Disponível em: $<$ https://tvefamosos.uol.com.br/colunas/leo-dias/2020/03/17/por-conta-docoronavirus-matheus-e-kauan-farao-show-virtual-para-fas.htm> Acesso em: 17 de março. 2020.

DIAS, Leo. Quanto custa para anunciar em uma live? Veja os preços. UOL, 20 de abr. 2020e. Disponível em: <https://tvefamosos.uol.com.br/colunas/leodias/2020/04/20/quanto-custa-para-anunciar-numa-live-veja-os-

precos.htm>. Acesso em: 20 Abr. 2020

DIAS, Leo. Gusttavo Lima supera Beyoncé, bate recorde de views e muda conceito de live. UOL, 29 de mar. 2020f. Disponível em: $<$ https://tvefamosos.uol.com.br/colunas/leo-dias/2020/03/29/gusttavo-limasupera-beyonce-bate-recorde-de-views-e-muda-conceito-de-live.htm> Acesso em: 30 de março. 2020.

Facebook. Concerts Consumer Journey Study. Facebook for business, 30 de jan. $2020 . \quad$ Disponível em: <https://www.facebook.com/business/news/insights/amp-up-your-connections- 
with-concertgoers >. Acesso em: 02 de abril. 2020

Festeja. Sobre o Festival. Festeja. 2020. Disponível em: <http://festeja.com.br/sobre>. Acesso em: 25 Mar. 2020.

GIL, Antonio Carlos. Métodos e Técnicas de Pesquisa Social. 6. ed. São Paulo: Editora Atlas S.A., 2008.

HOBSBAWN, Eric. Tempos Fraturados. Companhia das Letras, 2013

Jornal de Brasília. Gusttavo Lima faz live de 5 horas e arrecada mais de R\$500 mil em doações contra coronavírus. Brasília, 2020. Disponível em: $<$ https://jornaldebrasilia.com.br/clica-brasilia/gusttavo-lima-faz-live-de-5-horas-earrecada-mais-de-r-500-mil-em-doacoes-contra-coronavirus/>. Acesso em: 31 de março. 2020.

LORENTZ, Braulio . Intérprete de Libras da live de Marília Mendonça fala sobre repercussão após performance. G1, 10 de abr. 2020. Disponível em:<https://g1.globo.com/pop-arte/musica/noticia/2020/04/10/interprete-de-

libras-da-live-de-marilia-mendonca-fala-sobre-repercussao-aposperformance.ghtml>. Acesso em: 10 Abr. 2020.

MARTINELLI, Inacio, A Economia da Experiência no contexto dos festivais de Música.Trabalho de conclusão de curso de Graduação da Escola de Comunicação da UFRJ, ECO, Publicidade. Rio De Janeiro, 2013.

Ministério da Saúde. O que é COVID-19?.gov.br. 2020. Disponível em:https:<coronavirus.saude.gov.br/sobre-a-doenca>. Acesso em: 17 Abr. 2020.

NIELSEN. IFPI. Global Music Report 2019 - State Of The Industry. Disponível em: <https://www.ifpi.org/news/IFPI-GLOBAL-MUSIC-REPORT-2019>. Acesso em: 12 de maio. 2020

OLIVEIRA, Marina. Marília Mendonça bate recorde mundial de público com live. POPMARK, 09 de abr. 2020. Disponível em:<https://propmark.com.br/mercado/marilia-mendonca-bate-recorde-mundialde-publico-com-live>. Acesso em: 10 Abr. 2020.

PADILHA, Luiza. Coronavírus: entenda como a pandemia afeta os festivais de música no Brasil e o posicionamento do Mapa dos Festivais. Mapa dos Festivais, 13 de mar. 2020. Disponível em: $<$ https://blog.mapadosfestivais.com.br/coronavirus-e-o-impacto-para-os-festivaisde-musica-no-brasil/>. Acesso em: 01 de abril. 2020

RIBAS, Dani.; GOMES, Renata. Números, festivais e os sentidos coletivos dada pandemia. DATA SIM, 2020. Disponível em: $<$ https://datasim.info/estudos/numeros-festivais-e-os-sentidos-coletivos-dapandemia/>. Acessado em: 15 de abril. 2020

SOM LIVRE. Lives e Relação de marca. Rio de Janeiro, 2020. 
VIDALE, Guilia. O que é o distanciamento social e por que isso é importante? Veja, 19 de mar. 2020. Disponível em: $<$ https://veja.abril.com.br/brasil/o-que-e-distanciamento-social-e-por-que-isso-eimportante/> Acesso em: 23 de março. 2020

YouTube. Políticas e Seguranças. Youtube About. 2020. Disponível em: $<$ https://www.youtube.com/int//pt-BR/about/policies/\#community-

guidelines>. Acesso em: 11 Mai. 2020 


\section{Anexo 1}

1. O festival de 2020 precisou ser cancelado, como foi esse processo para a equipe que trabalha no festival?

2. Quais providências foram tomadas?

3. Quais foram as decisões mais difíceis?

4. Quais ações foram tomadas pelo o Festeja durante esse período de isolamento social?

5. Como foi a comunicação com o público?

6. Como estão planejando a retomada?

7. O que você acha que vai mudar neste mercado? 


\section{Anexo 2}

1. Qual a sua faixa etária

2. Qual o seu gênero?

3. Você assistiu a alguma live? Quais?

4. Qual live você mais gostou? Por quê?

5. Qual live você menos gostou? Por quê?

6. Como você busca informação sobre as lives?

7. Quando o período de isolamento social acabar você vai continuar assistindo as lives? Por quê?

8. Você pagaria para assistir uma live? Por quê?

9. Assim que acabar o isolamento social, você pretende frequentar eventos ao vivo?

10. Caso não, quando pretende retomar?

11. Você se lembra de alguma marca relacionada a alguma live?

12. Você passou a consumir alguma marca depois de alguma live? 